\title{
Involvement of Testosterone Signaling in the Integrity of the Neurovascular Unit in the Male: Review of Evidence, Contradictions, and Hypothesis
}

\author{
Delnia Ahmadpour Valérie Grange-Messent
}

Sorbonne Université, INSERM U1130, CNRS UMR 8246, Neuroscience Paris-Seine, Institut de Biologie Paris-Seine, Paris, France

\section{Keywords}

Adult male brain - Testosterone - Blood-brain barrier .

Neuroinflammation · Neurovascular unit

\begin{abstract}
Age-related central nervous system function decline and increased susceptibility of females compared to males with respect to prevalence of several neurodegenerative and neuropsychiatric diseases are both based on the principle that hormonal factors could be involved. These cerebral disorders are characterized by an alteration of blood-brain barrier (BBB) properties and chronic neuroinflammation, which lead to disease progression. Neuroinflammation, in turn, contributes to BBB dysfunction. The BBB and its environment, called the neurovascular unit (NVU), are crucial for cerebral homeostasis and neuronal function. Interestingly, sex steroids influence BBB properties and modulate neuroinflammatory responses. To date however, the majority of work reported has focused on the effects of estrogens on BBB function and neuroinflammation in female mammals. In contrast, the effects of testosterone signaling on the NVU in males are still poorly studied. The aim of this review was to summarize and discuss the literature, providing insights and contradictions to highlight hypothesis and the need for further investigations.
\end{abstract}

(c) 2020 S. Karger AG, Basel

\section{Introduction}

The reproductive effects of sex hormones, namely estrogens and androgens, are well known. Furthermore, it is increasingly apparent that these hormones have major actions on nonreproductive systems such as the central nervous system (CNS), controlling homeostasis, development, and some behaviors for instance $[1,2]$. These effects can be relevant throughout the lifespan of an organism and are not limited to the reproductive period [1-3]. Additionally, they have a profound influence on both sexes and are not restricted to one sex or the other [1]. One such example of the effects that sex steroids have on nonreproductive target tissues is their impact on cerebral blood vessels. Estrogens and androgens both regulate vascular tone, angiogenesis and endothelial cell (EC) survival, oxidative stress, and inflammatory responses in cerebral blood vessels [1], but the actions of estrogens and androgens often oppose each other [4]. Moreover, the expression of the respective receptors of estrogens and androgens suggests that cerebral blood vessels are directly targeted by sex steroids [5]. The protective effects of other classes of sex steroids such as progestins, including progesterone, have also been documented [6].

Numerous therapeutic approaches aim to target the emerging effects of steroid deprivation and/or supple- 
mentation for amelioration of several CNS conditions [7, 8]. Although many studies have investigated the therapeutic potential of estrogens and progesterone in bloodbrain barrier (BBB) function in females $[8,9]$, much less attention has been devoted to clarifying the impact of estrogens and androgens in males. The mechanisms underlying the effects of testosterone signaling on the neurovascular unit (NVU) in males are complex and still poorly studied. Currently, to our knowledge no review is available on this subject, and data reveal evidence but also contradictions. Thus, the intention of our review was to synthesize the literature data to bring out hypotheses and highlight the need for further investigations.

We present a summary of the distribution of sex steroid receptors, mediating testosterone effects, in the male brain. We then review and discuss data concerning the effects of testosterone on cerebral microvessels, focusing on $\mathrm{BBB}$ permeability modulation. We also present an overview of testosterone involvement in neuroinflammation and oxidative stress responses and their relation with BBB alterations.

\section{Blood-Brain Barrier}

In the CNS, cells require a stable microenvironment, which is guaranteed by a complex cellular and molecular system involving brain microvessels and their close environment referred to as the $\mathrm{BBB}[10,11]$. Indeed, the $\mathrm{BBB}$ is a highly regulated specific interface that maintains cerebral homeostasis to ensure neuronal activity. Indeed, the function of the $\mathrm{BBB}$ underlies the regulation of all vital functions of an organism. As such, BBB dysfunction can lead to many brain diseases and complicate recovery from injuries and insults $[11,12]$.

The walls of cerebral blood vessels are formed of ECs that are sealed by continuous intercellular molecular binding systems including adherens junctions and tight junctions (TJs) [13] that limit paracellular diffusion [14] (Fig. 1). The major transmembrane components of TJs are claudins, occludin, and junctional adhesion molecules [15]. They interact with the actin cytoskeleton via cytoplasmic TJ accessory proteins, including zonula occludens (ZO) proteins [16] (Fig. 1). In both mice and humans, claudin- 3 and claudin-5, ZO-1, and occludin have been described as the predominant proteins found at the TJs [17]. Claudins are crucial for the paracellular sealing function, hence, they directly determine barrier function [18]. However, the presence of claudin-3 in TJs of mouse BBB ECs has been recently called into question: immunodetection of claudin-3 in mouse brain ECs is thought to be an artifact due to antibody cross-reactivity with an un- disclosed endothelial junction antigen still present in mice deficient in claudin-3 [19]. C57BL/6J mice lacking claudin-3 expression display an intact $\mathrm{BBB}$ and do not show any signs of BBB dysfunction [19]. Claudin-5 knockout mice, however, have a significant paracellular ionic selectivity defect $[20,21]$. A review published early in 2019 provides a comprehensive overview of the role of claudin-5 and its regulation in physiological and pathological conditions [18]. Likewise, disassociation of the ZO-1 junctional complex, which typically serves to stabilize TJs, leads to the breakdown of BBB integrity [22]. The adherens junctions transmembrane components cadherin and nectin anchoring to cytoplasmic components such as catenin and afadin, respectively, are also involved in BBB integrity [23, 24] (Fig. 1).

In addition to the intercellular binding systems that limit paracellular diffusion, cerebral ECs also lack fenestration and exhibit extremely low rates of transcytosis, both of which greatly limit transcellular diffusion [25]. Both features arise from several changes to EC morphology and biochemistry that occur during embryonic development and allow the transition from a permeable to a continuous vessel [26]. BBB is present throughout the CNS except in certain unique regions of the brain, the circumventricular organs. The circumventricular organs are characterized by fenestrated capillaries permeable to blood-borne molecules, and the interface ensuring the cerebral homeostasis in these cerebral areas is constituted by specific cells called tanycytes. Those cells, lining cerebral ventricles, are sealed by TJs preventing the extravasation of molecules from fenestrated capillaries to the parenchyma via the cerebrospinal fluid, thus forming the blood-CSF barrier [see 27 for a review].

The control of substance exchange between blood and cerebral parenchyma is also mediated by specific carrier systems present in EC abluminal or luminal plasma membranes (Fig. 1). As such, the ability of macromolecules, fluids, and cells to cross endothelial barriers depends on charge, size, and binding characteristics [28]. Instead of passive diffusion, the supply of nutrients into the CNS occurs via active influx transporters such as glucose transporter 1 (GLUT-1), whereas elimination of metabolites occurs via transporters of two major membrane transporter families, the ATP-binding cassette family and the solute carrier transporter superfamily [29]. Notably, efflux transporters (e.g., P-glycoprotein, breast cancer resistance protein, and the organic anion transporter 3) are also responsible for the transport of several classes of pharmaceutical drugs [30, 31]. Due to their restrictive nature, those efflux transporters can also be major obstacles 


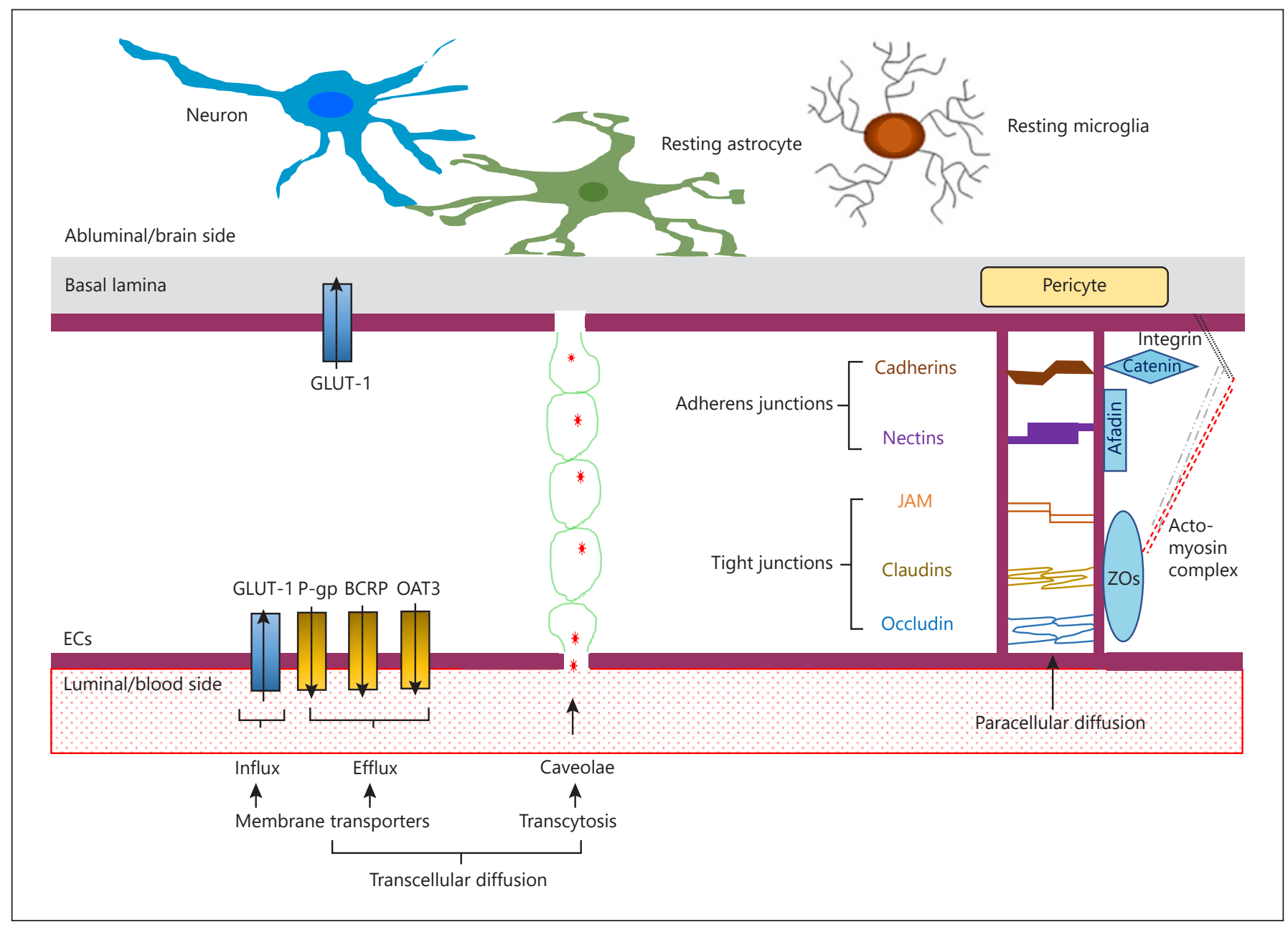

Fig. 1. The major cellular elements of the BBB localized at CNS microvessels are comprised of a continuous layer of ECs, basement membrane cells, pericytes, microglial cells, neurons, and astrocyte end-feet. BBB, blood-brain barrier; BCRP, breast cancer resistance protein; CNS, central nervous system; ECs, endothelial cells; GLUT-1, glucose transporter 1; JAM, junctional adhesion molecule; OAT3, organic anion transporter 3; P-gp, P-glycoprotein; ZOs, zonula occludens proteins. in the central distribution of many therapeutic agents for treating CNS diseases. Many lipid-soluble molecules, such as certain therapeutic drugs, are the substrates of efflux transporters, but some of them limit their absorption in order to protect the brain against potentially harmful exogenous substances [31, 32].

In addition to active protein transporters, endocytic vesicles serve as another major transcellular pathway accounting for BBB permeability in brain injury models [32, 33] (Fig. 1). Caveolae are non-clathrin-coated vesicles with plasma membranes enriched in caveolin (Cav) proteins, involved in receptor-independent transport of blood-borne molecules such as albumin $[32,34]$. To date, Cav-1, Cav-2, and Cav-3 isoforms have been identified in

Testosterone and the Neurovascular Unit in Males murine, bovine, and human cerebral endothelial and astroglial cells [35].

The BBB represents a complex cellular system that consists not only of ECs, but also of pericytes embedded in basal lamina surrounding ECs, and astrocytic end-feet anchored to this basal lamina. ECs, pericytes, basal lamina, astrocytic end-feet, and their neighboring microglial cells and neurons are collectively named the NVU (Fig. 1); they govern $\mathrm{BBB}$ development, along with its maintenance and integrity [13].

Pericytes cover a large part of the abluminal surface (between 22 and 99\% [10]) of the endothelium and contribute to the stability of microvessels [36]. Their position and abundance within the cerebral capillaries suggest that 
these cells play a major role in BBB integrity. To date, it has been hypothesized that pericytes would deliver angiogenic factors that regulate permeability and vascular remodeling $[37,38]$, and that they would have contractile capabilities to allow them to regulate blood flow through the capillaries [39]. Moreover, pericytes play a major role in the differentiation of ECs during fetal life, even before the appearance of astrocytes [40]. The recruitment of pericytes to endothelium and the interaction between the two are essential factors for the formation, maturation, and maintenance of the BBB [40-42].

The basal lamina forms a continuous network of extracellular matrix (ECM) composed of type IV collagen, laminin, nidogen, heparan sulfate, elastin, and various proteoglycans and glycoproteins [43]. The interaction between endothelial integrin, laminin, and other ECM proteins allows ECs to be anchored onto this basal lamina [44]. In addition to its structural role, ECM degradation is associated with an increase in paracellular permeability of the BBB [45].

Glial cells including microglial and astrocytes also represent an important element of the NVU. Microglial cells were described for the first time in 1919 by Del Rio-Hortega as a specific type of glial cell [see 46 for a review]. When circulation begins to form at the CNS, at a time when the $\mathrm{BBB}$ is still permissive, some microglial cell precursors enter the CNS through the vascular network [see 47 for the different hypotheses about the origin of microglia]. Those microglial cells that enter the brain parenchyma during embryonic development then branch out and remain quiescent [48]. Microglial cells are activated during inflammatory reaction or immune challenge in the CNS and then differentiate into resident CNS macrophages [45, 49]. Upon immune challenge or following microglia activation, astrocytes also produce inflammatory cytokines [50, 51]. In addition, astrocytes are pivotal in the formation of TJs of the ECs, the promotion of the enzyme system gamma-glutamyltranspeptidase involved in amino acid transport across the $\mathrm{BBB}$, the differentiated distribution of transporters present in the luminal and abluminal plasma membrane of the ECs, and ionic concentrations at the BBB [51-53].

Dysfunction of the BBB is associated with neurological damage and disease [54]. Disruption of the BBB is also associated with peripheral diseases such as diabetes [55] and nonneural, inflammation-related pathologies [56]. Alteration of the cells of the NVU upon aging, inflammatory activation, oxidative stress, or neuropsychiatric and neurodegenerative diseases leads to $\mathrm{BBB}$ dysfunction [44], which, in turn, contributes to the progression of neurological diseases $[17,44]$.

\section{Testosterone}

Testosterone was classically delineated as a male-specific hormone according to its marked synthesis in the testes and its contribution to phenotypic and reproductive sex differences [2].

The biosynthesis of testosterone from cholesterol has been demonstrated in many tissues in addition to Leydig cells of the testes (in males). These include the brain (hippocampus) and liver and, to a lesser extent, the adrenal cortex zona reticularis and zona fasciculata in both males and females [57]. Testosterone, which is a precursor of ovarian estrogens, is also present in females, but at lower concentrations $(0.5-1 \mathrm{ng} / \mathrm{mL}$ in adult women vs. $3-8 \mathrm{ng} /$ $\mathrm{mL}$ in adult men) [58]. Testosterone levels are sensitive to many internal and external factors and mainly fluctuate with aging $[58,59]$. Indeed, aging in men is accompanied by a progressive lowering of the serum testosterone level, in parallel with a decline in several CNS functions [6063]. This provides a logical reason to increase research to determine whether testosterone acts as a protective factor against several CNS disorders [64]. In addition to agerelated circulating testosterone changes, there are obvious sex differences in the prevalence of neuropsychiatric (e.g., depression, anxiety disorder, and anorexia nervosa) and neurodegenerative (e.g., cognitive decline, autoimmune diseases, Alzheimer disease [AD], and Parkinson disease [PD]) diseases, with a higher incidence in females than in males $[8,64]$. The reasons for sex differences are still unclear, and a better understanding of how the state of being male limits these CNS disorders is still lacking. It appears that sex bias is partly due to the protective effect of testosterone or to the presence of the $\mathrm{Y}$ chromosome in males $[58,65]$. A recent review has finely summarized the sex differences in cerebrovascular function, highlighting the evidences for sex steroid hormone mediation in numerous cerebrovascular regulations and pathologies [66].

Previously, testosterone research was almost entirely focused on reproductive issues. However, it is now known that testosterone is a regulator of fundamental physiological processes of nonreproductive tissues such as cardiac and skeletal muscle, or of the development and function of the immune and nervous systems [1], including cerebrovascular tissue [67-70]. Outside the brain, testosterone has a key effect on the cardiovascular system by regulation of the vascular tone [71]. The greater incidence of clinical manifestations of heart disease in men and postmenopausal women compared with premenopausal women translates a sex steroid hormones-induced sex difference for the vascular tone with a possible vascular 
protective effect of female sex hormones. It has been suggested that this sex difference in vascular tone is mediated at least in part by specific sex hormone receptors [68]. Nevertheless, the role of testosterone in vascular contractility is debated. A number of studies have shown that testosterone facilitates vasoconstriction in rats (in vivo and in vitro) $[72,73]$, while other data have reported a vasodilator effect in rats and rabbits $[74,75]$. Vascular mechanisms of testosterone have been thoroughly reviewed very recently [76]. In the brain, the regulation of cerebrovascular items is mediated through several mechanisms such as for instance angiogenesis, vascular contractility, and control of $\mathrm{BBB}$ permeability.

\section{Distribution of Sex Steroid Receptors Mediating Testosterone Effects in the Male CNS}

Sex steroids mediate their action via members of the nuclear receptor superfamily. These are expressed widely throughout the CNS by multiple cell types, but especially in brain areas involved in cognitive and reproductive behavior as well as in neuroendocrine function [2]. Testosterone exerts its effects on the organization and function of the CNS by either androgen receptors (ARs) or estrogen receptors (ERs) after undergoing neural aromatization to estradiol (about $0.3 \%$ ) [1,77]. The reductase enzyme catalyzes the conversion of about $7 \%$ of testosterone to dihydrotestosterone (DHT), which is 2.5 - to 10 -fold more potent than the former $[78,79]$. ER- and AR-mediated signaling pathways modulate several CNS activities by both genomic and nongenomic actions $[5,79]$. To describe sex steroid receptor localization within the adult CNS, mRNA expression patterns of ARs and ERs were investigated in adult rats [79-81] (Fig. 2). In males, nuclear ARs are expressed in the cortex and hippocampus (CA1 and CA2/CA3 regions), which control the regulation of cognitive behavior. However, ARs are also widely expressed in the olfactory bulb, the medial amygdala, the bed nucleus of the stria terminalis, and the preoptic area (POA) of the hypothalamus involved in neuroendocrine functions and reproductive behavior [79] (Fig. 2). It is also known now that nuclear ARs are present in neurons and glial cells as well as in cerebral blood vessels at the level of smooth muscle and the endothelium [5].

Neural estrogens exert their effects through interaction with two nuclear ERs: ER $\alpha$ and ER $\beta$. A comparative study provided evidence that nuclear forms of both ERa and $\operatorname{ER} \beta$ are expressed in the male rat CNS; some regions express exclusively ER $\alpha$, e.g., at the level of the ventrome-

Testosterone and the Neurovascular Unit in Males dial hypothalamic nucleus, while others express only $E R \beta$, e.g., paraventricular nuclei. In contrast, other regions like the bed nucleus of the stria terminalis, the medial and cortical amygdaloid nuclei, the POA, as well as the periaqueductal gray and spinal trigeminal nuclei contain both forms of ER mRNA $[79,80]$. The cerebral cortex and hippocampus also contain both ER mRNAs, giving a lower hybridization signal for ER $\alpha$ than for $\operatorname{ER} \beta$. This suggests the involvement of ER $\beta$ in cognition and memory $[2,79,80]$ (Fig. 2). It is noteworthy that the highest level of ERa mRNA expression is in the hypothalamus and amygdala and is related to regulation of sexual behavior and the hypothalamic-pituitary-gonadal axis [82].

In addition to their neural expression, specific receptors for gonadal steroids are expressed in the cerebrovascular tissue [5]. They can thereby control the integrity of the $\mathrm{BBB}$ by modulation of membrane transporters, intercellular molecular binding systems, and neuroinflammatory responses $[67,69,83]$, as we will discuss further below. Additionally to their specific receptors, the metabolic enzymes for gonadal steroids have been found in cerebral blood vessels [5].

\section{Testosterone-Induced Neuroprotection in the Male CNS}

As evoked above, sex differences in the prevalence of neurological disorders and diseases can be explained by neuroprotective effects of testosterone in males. Recently a pivotal role of androgenic signaling in modulation of neural activity within the CNS through myelination and remyelination of neurons and synaptic plasticity has been documented $[68,84]$.

The decreased susceptibility of men compared to women to inflammatory autoimmune disorders such as multiple sclerosis is also described in some mouse models like the SJL/J mouse. This exhibits spontaneous myopathy, associated with an increased susceptibility to autoimmune diseases. Castrated SJL/J mice showed greater demyelination and inflammation within the spinal cord than sham-operated males $[1,8,58,64]$. Furthermore, recent data obtained in a mouse model of chronic demyelination [85] and lysolecithin-induced demyelination [64] have allowed the effects of the androgenic pathway on myelin repair and remyelination processes to be established.

It is also well known that synaptic changes are involved in memory impairment occurring in the hippocampus of patients with $\mathrm{AD}$ [86]. A beneficial role of testosterone in 


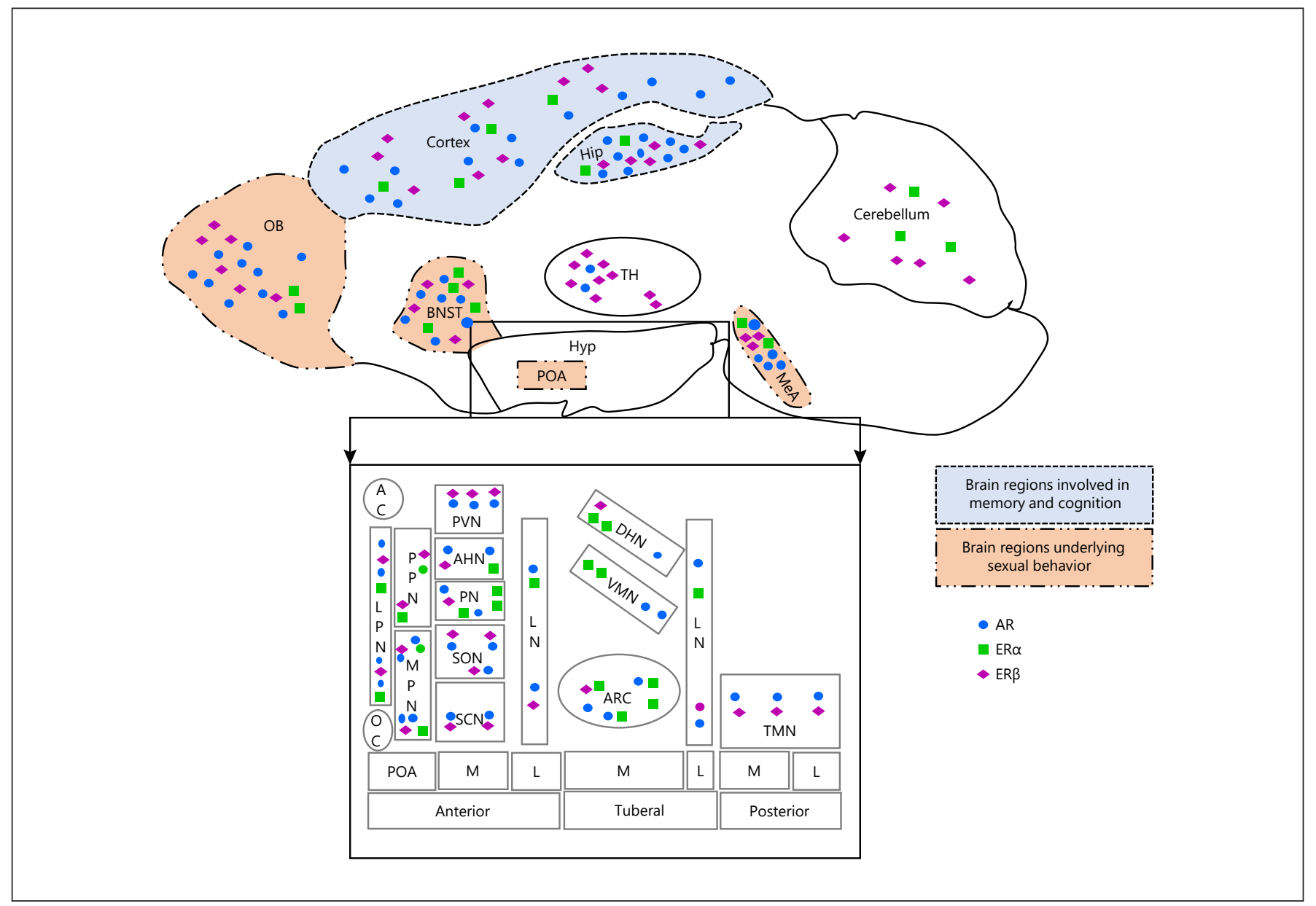

Fig. 2. Overview of a whole male brain with a close-up view of the position of hypothalamic nuclei pointing out the relative location and density of AR (blue circles) and ER (ERa, green squares; ER $\beta$, pink diamonds) mRNA distribution using in situ hybridization analysis in a male rat [79-81]. AC, anterior commissure; $\mathrm{AHN}$, anterior hypothalamic nucleus; AR, androgen receptor; ARC, arcuate nucleus; BNST, bed nucleus of the stria terminalis; DHN, dorsomedial hypothalamic nucleus; ER, estrogen receptor; Hip,

improving cognitive performance in mice and rats by enhancing the hippocampal protein network, which is critical for synaptic transmission and plasticity, has been described $[87,88]$. Furthermore, the expression of ARs, not only in nuclei [89] but also at extranuclear sites of hippocampal neurons [90], has revealed the involvement of testosterone and DHT in neural activity and synaptic function. Gonadectomy also decreases the density of spinal synapses in the male rat hippocampus [91]. Replacement therapy by added DHT or testosterone restores spinogenesis through AR signaling, which rapidly promotes kinase networks in neurons [92]. In addition, despite the fact hippocampus; Hyp, hypothalamus; L, lateral; LN, lateral nucleus; LPN, lateral preoptic nucleus; M, medial; MeA, medial amygdala; MPN, median preoptic nucleus; OB, olfactory bulb; OC, optic chiasma; PN, periventricular nucleus; POA, preoptic area; PPN, periventricular preoptic nucleus; PVN, paraventricular hypothalamic nucleus; SCN, suprachiasmatic nucleus; $\mathrm{SON}$, supraoptic nucleus; $\mathrm{TH}$, thalamus; TMN, tuberomammillary nucleus; VMN, ventromedial nucleus.

that there are no ARs in the dentate gyrus of the adult male rat hippocampus, it has been demonstrated that $\mathrm{AR}$ signaling induces neurogenesis via modulation of the survival of new neurons in this area of the brain [93].

In many studies concerning psychiatric disorders, women are reported to have a higher incidence of depression than men [94]. Aging is also associated with an increased prevalence of depression in both sexes [95]. Depression can be associated with alterations in the proliferation and survival of hippocampal neurons: evidence indicates a role of androgenic signaling in the survival of new neurons in the hippocampus of young adult males [64]. 
Chronic stress is also associated with reduced neurogenesis and expression of synaptic proteins in the CA1 and CA3 regions of the adult hippocampus [96]. The stress response is mediated through the production of glucocorticoids [97], and it is well known that testosterone reduces glucocorticoid release [95, 98].

In men, the relatively high levels of circulating testosterone compared to women is correlated with a higher incidence of strokes [99]. It was shown that the high levels of testosterone and DHT may contribute toward sensitivity to cerebral ischemia in young males $[100,101]$. Emerging experimental studies, however, have indicated that the decline of testosterone level upon aging in males can be associated with an increased risk of stroke [102]. These data describe testosterone's dose-dependent neuroprotective and neurodamaging effects in experimental models of cerebral ischemia. Finally, recent experiments in vitro have shown that gonadal hormones may also be involved in the suppression of neuronal apoptosis during ischemic disorders: testosterone and DHT suppress neuronal cell death induced by oxygen-glucose deprivation/ reoxygenation in hippocampal slice cultures [103].

In many brain diseases, disorders, traumas, or strokes, neuronal damage is associated with an inflammatory response [104] and a dysfunction of the BBB [105]. However, in a model of multiple sclerosis a partial uncoupling of inflammation and neurodegenerative process has been shown [106]. This study also suggests that BBB dysfunction may persist regardless of inflammatory signals.

Recent data have suggested that the cross talk between testosterone and glial cells, astrocytes or microglia, participates in the neuroprotective effect. This is achieved by attenuating neuroinflammation and oxidative damage during acute traumatic brain injuries such as stroke and hypoxia [58, 107-109]. However, it has been hypothesized that the control of reactive gliosis such as an increase in astrocyte and microglia activation, a key event in neuroinflammation, is part of the testosterone neuroprotective mechanism [110]. We will devote another part of this paper to a detailed discussion of testosterone effects upon neuroinflammation (see below).

\section{Testosterone and Cerebral Blood Vessels}

Testosterone modulates vascular function through several mechanisms including, but not limited to, angiogenesis and $\mathrm{BBB}$ permeability.

Testosterone and the Neurovascular Unit in Males
Impact of Testosterone on Angiogenesis and

\section{Vasculature Formation}

The development of the BBB occurs in several steps, beginning with angiogenesis from preexisting vessels around embryonic day E10 in mice [26] (Fig. 3a). It has been demonstrated that testosterone modulates vasculature function and integrity via several mechanisms that involve vasculature formation, e.g., proliferation, migration, and differentiation [111]. The patterns of circulating levels of testosterone in the male mouse from birth to adulthood are illustrated in Figure 3b [112]. Several researchers have focused their activities on the impact of testosterone on angiogenic mechanisms in cardiovascular regeneration and cerebral angiogenesis in adults [1, $62,113]$. However, the role of testosterone in CNS angiogenesis during fetal life has remained largely unexplored. In cultured human umbilical ECs, testosterone induces EC migration through myosin activation and actin cytoskeleton remodeling [114]. It also increases formation of EC tubes by stimulating Smad1 phosphorylation. This represents one possible mechanism for testosterone-enhanced angiogenesis [115]. An in vitro study using human dermal fibroblasts revealed that DHT is a regulator of vascular endothelial growth factor (VEGF) secretion, the key mediator of angiogenesis in both CNS and nonCNS tissues [62]. In addition, VEGF has a therapeutic potential for the induction of neuroprotection, neurogenesis, and cerebral angiogenesis after ischemic disorders such as stroke [116]. Furthermore, histological and transcriptomic analyses of adult female robins and canaries treated with testosterone reveal that this hormone induces angiogenesis in song control nuclei. This is associated with upregulation of VEGF, VEGF receptors, and brain-derived neurotrophic factor [117-119].

\section{Impact of Testosterone on Cerebral ECs and BBB}

The impact of sex steroid hormones as therapeutic agents has received special attention, with emphasis being placed on their neuroprotective effects. However, only a few studies have focused on the influence of sex steroids on the BBB and the NVU in both physiological and pathological conditions. Relatively little is known about testosterone compared to estrogens and progesterone due to (a) controversial results concerning its involvement on vascular endothelium function, (b) debate as to therapeutic aspects (dose, duration, and health status), (c) misuse or abuse for nonmedical purposes, and (d) complicity of action due to interaction with multiple ERs.

The maintenance of the BBB as a crucial interface, separating peripheral circulation and the CNS, requires per-

Neuroendocrinology 2021;111:403-420 


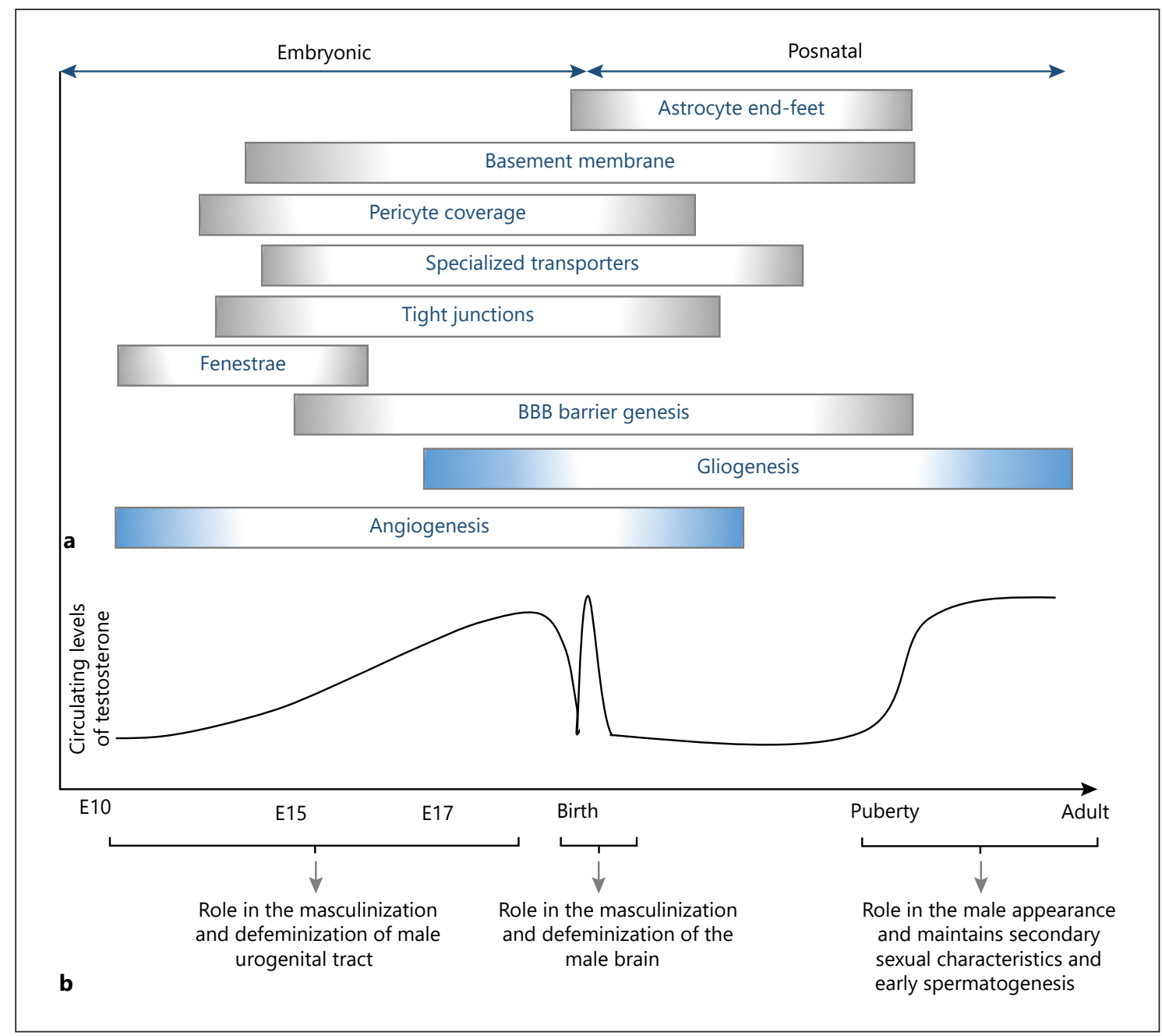

Fig. 3. a Developmental timeline of the BBB setup in the murine CNS [26]. b Pattern of circulating levels of testosterone in the male mouse from birth to adulthood [112]. BBB, blood-brain barrier; CNS, central nervous system; E, embryonic days.

fect interaction between all components of the NVU. Additionally, altering critical properties of the BBB including, but not limited to, membrane transporters, vesicular pathways, basal lamina, and TJ proteins of ECs could lead to a modification of microvascular integrity, i.e., brain homeostasis. Testosterone modulates cerebral EC and BBB function through the modulation of key elements of this complex cellular system.

\section{Endothelial Membrane Transporters}

To date, only very limited data exist concerning testosterone effects on the regulation of membrane transporters at the BBB. OAT3, which mediates the efflux transport of uremic toxin and neurotransmitter metabolites such as dopamine metabolite [120], is expressed at the BBB [13]. The expression of OAT3 in male rats is higher than in females [121], and ARs regulate the expression and uptake rate of OAT3 in BBB cells (Fig. 4) [83]. It is noteworthy that the dopaminergic system participates not only in sexual behavior processes, but also in regulation of cognitive behavior [122].

Sodium-dependent and -independent glucose transporters represent the two types of glucose transporter that regulate the uptake of glucose as a crucial energy source at the level of the BBB [123]. The activity of these transporters is subject to modulation in a variety of neuropathological and neuropsychiatric disorders, including $\mathrm{AD}, \mathrm{PD}$ [124], and depression [125]. A study proposed 


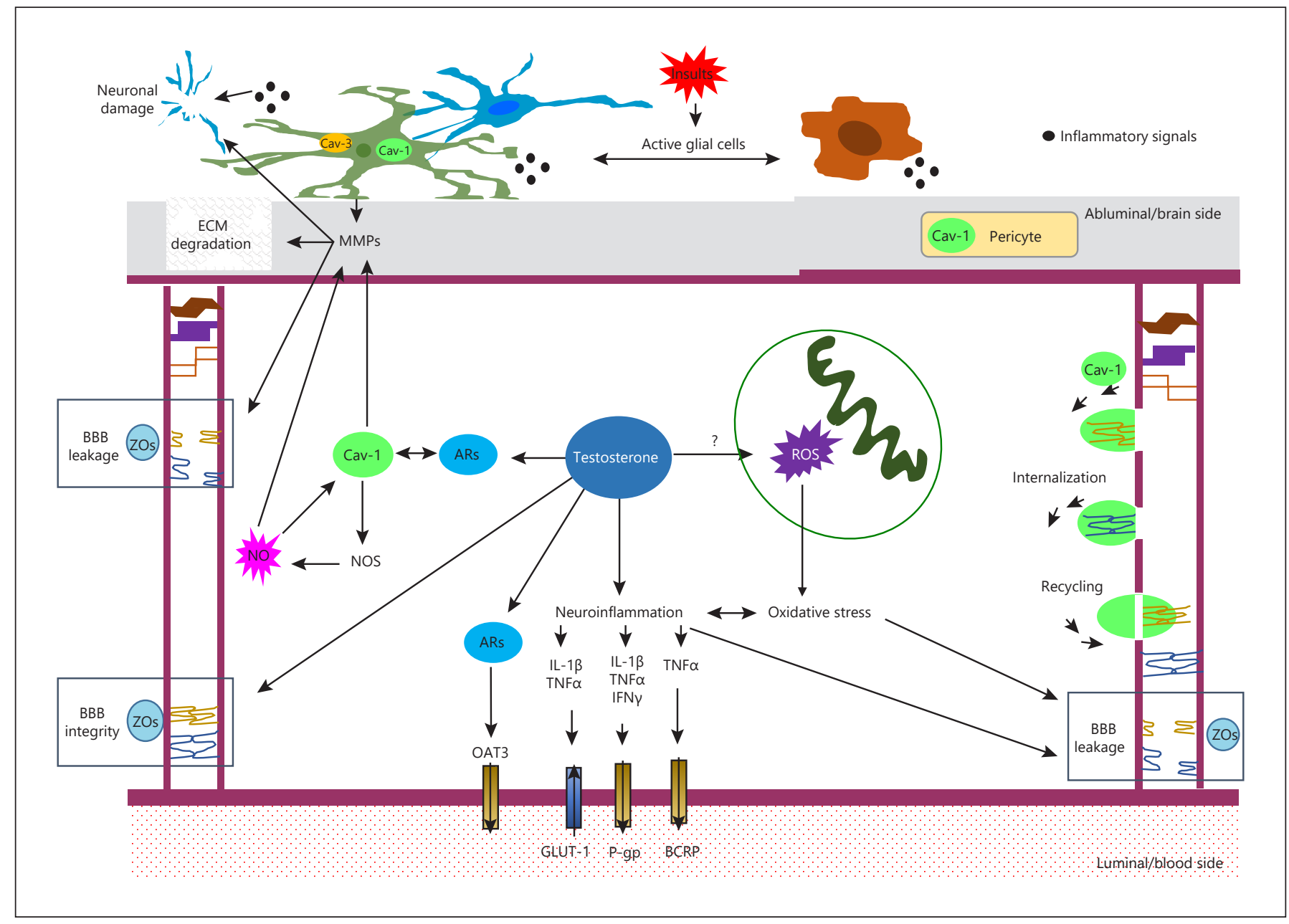

Fig. 4. State of the art schematic representation of testosterone signaling-induced cellular and molecular interactions in the BBB system, highlighting in particular the Cav-1/NO/MMP pathway involvement. Testosterone controls the integrity of the BBB by preserving the intercellular molecular binding protein degradation by regulating endothelial transporter expression or activity and by decreasing inflammatory response. Cav-1 protein is known as an AR coactivator. Cav-1 protein is expressed by brain ECs and pericytes, while reactive astrocytes express both Cav-1 and Cav-3. Cav1 is responsible for (1) internalization and recovery of TJ proteins during a brain insult and (2) inhibition of NO production and consequently inhibition of MMP activity, thereby preventing TJ protein hydroxylation, ECM degradation, and neuronal loss. Briefly, the CNS response to insult and injury is manifested by gliosis. The inflammatory responses are directly associated with neuronal loss, degradation of TJ proteins, decrease in the number of GLUT-1, and decrease in the activity of P-gp and BCRP transporters. Testosterone, in turn, decreases inflammatory mediators. In addition, ARs positively regulate the expression and uptake rate of OAT3. Oxidative stress caused by overproduction of ROS activates inflammatory factors. The cross talk between oxidative stress and neuroinflammation causes BBB leakage. The involvement of testosterone in oxidative stress is not well known. AR, androgen receptor; $\mathrm{BBB}$, blood-brain barrier; $\mathrm{BCRP}$, breast cancer resistance protein; Cav, caveolin; CNS, central nervous system; ECM, extracellular matrix; ECs, endothelial cells; GLUT-1, glucose transporter 1 ; IFN $\gamma$, interferon gamma; IL- $1 \beta$, interleukin 1 beta; MMP, matrix metalloproteinase; NO, nitric oxide; NOS, nitric oxide synthase; OAT3, organic anion transporter 3; P-gp, P-glycoprotein; ROS, reactive oxygen species; TJ, tight junction; TNFa, tumor necrosis factor alpha; ZOs, zonula occludens proteins.

ulators of glucose transporters [124, 127]. To date, there has been no report concerning testosterone effects on these transporters' activities. Thus, the testosterone effects on membrane transporters at the BBB are not well 
understood, and this subject needs investigation. However, it will not be surprising that testosterone could act as a modulator of influx and/or efflux transporters partly through the modulation of inflammatory mediators. Indeed, the impact of the inflammatory mediators on BBB transporters has been described [128, 129]. For instance, the inflammatory mediators, such as tumor necrosis factor alpha (TNFa), interleukin 1 beta (IL-1 $\beta$ ), and interferon gamma can decrease the activity of P-glycoprotein at the level of the BBB (Fig. 4) [130]. P-glycoprotein contributes to the efflux of brain-derived amyloid into blood. In addition, $\mathrm{TNFa}$ reduces the functional activity of breast cancer resistance protein (Fig. 4) [131], which could alter the penetration of their substrates into the brain. Recently, evidence has shown that depletion of gonadal testosterone by castration of male mice induces upregulation of IL-1 $\beta$ and TNFa in the POA [67] (Fig. 4), although the effects of these shifts upon membrane transporters were not evaluated.

Transendothelial Vesicular Transport Pathway

As already mentioned, caveolae are known as a major transcellular pathway in brain injury models. It was shown that the components of the caveolae plasma membranes, Cav proteins, play a critical role in signal transduction [77]. In addition to brain ECs, the Cav-1 protein has been described in vascular pericytes [132], while both Cav-1 and Cav-3 have been found in vivo and in vitro in reactive astrocytes (Fig. 4) [132, 133].

It is important to address the controversy concerning the role of Cav-1 in regulating vascular permeability. An in vivo study in rats showed an enhancement of permeability of the BBB through upregulation of the expression level of Cav-1 [34]. Nonetheless, data obtained from Cav1 and Cav- 2 knockout mice have shown a higher vascular permeability and a lower lesion volume, respectively, after a stroke compared to wild-type mice [134]. This suggests a positive role of Cav-1 in the maintenance of the integrity of the BBB in contrast to Cav-2. Cav-1 knockout ischemic brains are also characterized by impaired angiogenesis and increased cell death [134]. The role of Cav-1 in $\mathrm{BBB}$ integrity in the context of neuropathology and neural recovery after ischemic stroke was reviewed very recently, and the discrepancies in the literature pertaining to the role of Cav-1 were discussed [135].

Data based on rat immunohistochemistry analyses showed that an increase in Cav-1 expression at the cortical lesion site of a cold injury blood vessel model is associated with loss of occludin and claudin-5 TJ proteins [136]. However, it has been suggested that Cav-1 expression con- tributes to the recovery of $\mathrm{TJ}$ proteins and $\mathrm{BBB}$ function after injury. There are clear results indicating that TJ proteins are either bonded or localized in caveolae, and internalization, but not degradation, of occludin and claudin- 5 through Cav-1 is responsible for alterations in brain endothelial barrier permeability during inflammation [137]. Recycling of internalized TJ proteins is crucial for recovery of the brain endothelial barrier integrity [137] (Fig. 4).

Despite confusion in the current literature concerning the roles of Cav-1 in the modulation of BBB integrity, thus far studies have provided evidence that Cav-1 could prevent oxidative and inflammatory injury as well as extracellular degradation of TJ proteins and matrices [137, 138]. The increase in Cav-1 upon brain injury may reflect its beneficial involvement in the recovery of BBB integrity in damaged CNS, but would not explain a detrimental role. We can also suppose that the effects of Cav-1 may be isoform, tissue, state of health, and dose-dependent. Further, Cav-1 may have different functions in different neurological dysfunctions. The exact mechanisms and explanations for these controversial results remain unclear, and this is an issue that needs further investigation.

There is evidence showing that nongenomic ARs can interact with numerous signaling molecules at the plasma membrane. Thus, ARs interacting with caveolae trigger numerous kinase-signaling pathways involving in particular the Src kinase, extracellular signal-regulated protein kinase, phosphoinositide 3-kinase, and protein kinase B [77]. Cav-1 protein is known as ARs coactivator [77, 139], allowing this nuclear receptor to efficiently mediate gene expression. Thus, it cannot be excluded that AR nongenomic activity indirectly influences activity of either genomic ARs or other nuclear receptors. Furthermore, a recent study showed a positive correlation between the level of Cav-1 and AR transactivation and sensitivity of ARs to ligand-dependent activation, confirming the role of Cav-1 as a convergent point for AR cross talk with other cellular signal transduction pathways (Fig. 4) [140]. Thus, given the importance of Cav-1 in modulation of the $\mathrm{BBB}$ integrity and its links with ARs, study of the molecular mechanisms underlying the interaction between the Cav1 protein and the AR requires further investigation.

\section{Basal Lamina and the Immediate Surroundings of ECs}

The basal lamina as an acellular membrane surrounding ECs has a pivotal role in BBB integrity [141]. Loss of basal lamina stability triggered by metalloproteases or collagenases is frequently observed in pathological manifestations involving BBB breakdown [142]. 
Nitric oxide (NO) is a diffusible gas which at basal concentration is dose-dependently capable of regulating numerous physiological functions (neuronal communication, vascular tone regulation, etc.) and at higher concentrations can cause disease (cell death) through multiple mechanistic pathways [143]. The basal concentration of $\mathrm{NO}$ derives from endothelial NO synthase (eNOS) enzyme activity, whereas deleterious effects are due to the activity of neuronal (nNOS) and inducible NOS (iNOS) isoforms [143].

NO mediates its physiological effects at least in part by the activation of matrix metalloproteinases (MMPs) during matrix reorganization [143]. MMP2, MMP3, and MMP9 are the main forms found in the brain and are the prime proteolytic enzymes particularly involved in the degradation of the ECM [144] and in neuronal damage [145-147]. Activated MMPs also lead to BBB leakage by catalyzing hydrolysis of the TJ proteins, thereby inducing their degradation [147-149] (Fig. 4). In addition, both MMP2 and MMP9 contain Cav-binding motifs, and there is direct evidence that Cav-1 can downregulate MMP activities and decrease BBB permeability in brain microvascular ECs during cerebral ischemia-reperfusion injury [150]. Moreover, Cav-1 protein regulates the activation of NOS by binding to all NOS isoforms that contain the Cav-binding motif, thereby inhibiting NO production (Fig. 4) [150]. In a recent investigation, the Cav-1/NO/MMP pathway has been suggested as a therapeutic target to ensure protection against cerebral ischemia-reperfusion injury (Fig. 4) [138]. Given the importance of the links between ARs and Cav-1, as mentioned previously, it could be hypothesized that AR would be another important partner of the Cav-1/NO/MMP pathway, ensuring BBB integrity.

Pericytes are located around the cerebral capillaries, and they share the basal lamina with ECs. Despite a decrease in pericyte numbers and ultrastructural changes in aging and age-related brain diseases such as $\mathrm{AD}$, in both human and preclinical models [151], there are no data concerning the effects of sex steroid hormones on pericytes. Further investigations in this regard are clearly required.

Interendothelial TJs

Cerebral ECs possess unique phenotypic properties due to the presence of continuous TJs, the lack of fenestration, minimal pinocytotic but more peptidase, and mitochondrial activity [26, 44]. Numerous biochemical components or pathophysiological states can directly or indirectly disrupt the NVU at both the structural and functional level. Such disruption leads to an increase in leakage across the BBB [69].

Abnormal cerebrovascular TJs have been detected in a wide range of diseases including ischemic stroke traumatic brain injury, $\mathrm{AD}$, and multiple sclerosis [44], as well as in physiological aging [13].

It is now well known that ovarian hormones influence $\mathrm{BBB}$ integrity with respect to limiting paracellular permeability via the preservation of TJ proteins $[69,152]$. However, the contribution of testosterone to the BBB TJs response is poorly defined.

The first conclusive evidence that under physiological conditions testosterone impacts TJ protein expression in males was obtained in our 2017 study [67]. This showed that castration of adult male mice significantly decreased the expression of TJ proteins (claudin- 5 and ZO- 1 but not occludin) in the hypothalamic POA, leading to changes in morphological arrangements and/or delocalization and disorganization of brain endothelial junction proteins. Additional results based on different molecular weight tracers, as a marker of BBB integrity, suggested that chronic depletion of testosterone induces defects in the BBB permeability in this region. Supplementation with testosterone after castration restores BBB impermeability and TJ integrity [67]. In connection with this point, the specific roles of the neural ARs and their signaling pathways are being studied. These results can be compared to those obtained in mice with a selective deletion of ARs in Sertoli cells, which reveal that ARs in Sertoli cells are pivotal for timely and complete blood-testis barrier formation. The absence of functional ARs represents a potential cause for delayed and defective (leaky and incomplete) barrier formation [153]. Thus far, these results suggest that androgenic signaling supports BBB integrity. However, this study does not shed light on whether the genomic or nongenomic steroid pathway mediates androgen effects.

\section{Testosterone and Neuroinflammation: Relationships with BBB Dysfunction}

Inflammation and innate immunity are believed to contribute to the occurrence and severity of pathogenesis and neurodegenerative diseases. Furthermore, as already mentioned, microglial activation that is involved in neuroinflammation represents one of the most frequent clinical characteristics of these disorders. In addition, reports have already pointed out rapid and progressive alterations of the brain endothelium during such diseases. In- 
terestingly, testosterone does not only regulate the development and function of the immune system, but also modulates neuroinflammatory responses. These should be neither underestimated nor neglected. In the context of neuroinflammation, further research has focused on the apparent roles of resident cerebral cells, including astrocytes and microglia.

This activation of microglia is directly associated with a dysfunction of the BBB [154, 155]. Microglia express a cytoplasmic marker, the ionized calcium binding adapter molecule 1 protein, which is upregulated during microglial activation $[156,157]$. The degree of activation of microglia appears to be correlated with the type and severity of the brain disorder [158]. Thus, activation is part of their primary action as mediators of responses to pathogens and injury. They have either protective (housekeeping functions) or destructive (buffering action) impacts on the CNS, depending on their state and the duration of activation [159]. Microglia are known as the source of proinflammatory cytokines (e.g., TNFa, IL-1 $\beta$, IL-2, IL-4, and IL-6), prostaglandins, chemokines, enzymes associated with inflammation (e.g., iNOS and COX-2) as well as inflammatory cytokines production [160]. By releasing cytokines such as TNFa, activated microglia induce neurotoxic reactive astrocytes (termed "A1") which might have harmful functions [161]. Numerous studies indicate that following CNS injury, reactive astrocytes upregulate both vimentin and glial fibrillary acidic protein [162, 163]. Astrocyte-inducible NOS has been described to play a major role in human neuroinflammation [164-166].

Gliosis corresponds to the reactive change of glial cells (microglia and astrocytes) in response to damage [167, 168]. This is conjugated with the modulation of local chemokines and cytokines, which govern inflammation (Fig. 4). Chronic gliosis may heighten the neurodegenerative process. Thus, neuroglia have been identified as a therapeutic target to halt inflammation in several neurodegenerative diseases [169].

The action of testosterone on reactive gliosis is not well documented yet. However, available evidence indicates that administration of testosterone, but not DHT, downregulates reactive gliosis after brain injury in male rats $[110,170,171]$. Recently, it has been shown that reactive astrocytes induce $\mathrm{BBB}$ disruption at least in part via the production of VEGF-A and thymidine phosphorylase in the case of inflammatory brain lesions [172].

Furthermore, we have shown that castration of male mice is associated with activation of neuroglial cells. This occurs via upregulation of inflammatory proteins such as COX-2 and iNOS as well as proinflammatory cytokines such as TNFa. Interestingly, supplementation of testosterone after castration suppresses these inflammatory features [67]. Data observed in a variety of cerebrovascular diseases and neurodegenerative disorders showed that the function of the BBB is compromised once a state of neuroglia activation is attained. This is accompanied by an increase in the expression and release of several proinflammatory molecules such as TNF $\alpha$ and IL-1 $\beta$ [173]. In addition, it has been proposed that in turn, BBB dysfunction contributes to the progression of neurodegenerative diseases [14]. However, due to lack of a key pathway, the link between neuroinflammation and disruption of the BBB is still poorly understood, and it remains difficult to determine whether $\mathrm{BBB}$ breakdown is a cause or a consequence of the inflammatory status.

\section{Testosterone and Mitochondria-Derived Oxidative Stress: Relationships with BBB Dysfunction}

The sensitivity of the $\mathrm{BBB}$ to oxidative stress is due to a high mitochondrial content $(8-11 \%$ of the endothelial cytoplasmic volume) in cerebral ECs, which is pivotal to maintain active transport [174]. Nevertheless, information concerning testosterone impact upon mitochondrial reactive oxygen species (ROS) generation in the $\mathrm{BBB}$ is still scarce.

The ROS and reactive nitrogen species (RNS) free radicals are derived from both endogenous and exogenous sources. They are well recognized for dual roles, acting as both deleterious and beneficial species. The mitochondrial respiratory chain is an important endogenous source and target of ROS [175] (Fig. 4). It is noteworthy that the intrinsic apoptotic pathway is mediated by mitochondria through ROS production. Increased ROS production induces oxidative stress, which has been reported to be involved in several pathological conditions such as cardiovascular disease. Furthermore, ROS activates inflammatory factors [176]. Interestingly, the mitochondria impairment disrupts EC TJs and increases BBB permeability, which is accompanied by deterioration as an outcome of neurodegenerative disorders (e.g., stroke, $\mathrm{PD}$, and $\mathrm{AD}$ ) [177]. In addition, oxidative stress induces inflammation, which can further increase oxidative stress activity (Fig. 4) [178]. Low testosterone levels [179, 180], aging [181], and testosterone deprivation [182] are risk factors for oxidative stress. It was shown that there is an inverse association between testosterone concentrations and oxidative stress markers in adult men [183]. In 
the CNS, there is evidence to indicate that testosterone improves mitochondrial membrane potential and reduces nuclear fragmentation and ROS generation in a human astrocyte cell model, acting via positive regulation of neuroglobin. The latter represents a key factor involved in cellular oxygen homeostasis [184]. To date, the involvement of testosterone in oxidative stress at the level of the NVU is still not well established and needs further investigation. The effects of testosterone upon oxidative status are still controversial, ranging from ROS generation to scavenging or chain breaking of ROS and RNS [185-188]. Numerous studies have indicated that the effect of testosterone in this regard is tissue-, sex-, and dose-dependent [189]. In prostate cancer cell lines, androgen signaling regulates the cytoplasmic dynamin-related protein, a key protein of the mitochondrial fragmentation machinery, that leads to cell death but not to cell division [190]. Moreover, it was shown that in these cell lines testosterone causes ROS and $\mathrm{H}_{2} \mathrm{O}_{2}$-induced apoptosis [191]. Like cerebral ECs, gastric parietal cells contain many mitochondria. Data based on gonadectomized male rats following testosterone supplementation suggested that testosterone could mediate mitochondria-associated apoptotic signaling in the gastric mucosa by reducing ROS generation and by impairing apoptotic processes [192]. However, it has been reported that androgens induce ROS generation through AR signaling in cultured vascular smooth muscle [193] and renal interlobar arteries [194].

\section{Conclusion}

The aim of this review was to present an overview of the literature data concerning the effects of testosterone on the NVU in males. It mainly emerges from these studies that (a) testosterone promotes cerebral angiogenesis and vasculature formation, (b) testosterone supports the integrity of BBB TJs, and (c) testosterone regulates some endothelial membrane transporters, although very few data are available yet. The effects of testosterone are mediated by either androgen or ERs and the mechanisms by which it regulates these features are usually not described. Nevertheless, ARs and their interaction with the Cav-1 protein would be involved in the BBB integrity by participation in the Cav-1/NO/MMP pathway.

Dysfunction of the BBB is often associated with an inflammatory status inducing a neurodegenerative process. However, the link between neuroinflammation and disruption of the $\mathrm{BBB}$ is still poorly understood. Data sug-

Testosterone and the Neurovascular Unit in Males gest that testosterone could prevent from gliosis reaction and upregulation of inflammatory proteins and could participate in reducing ROS generation and limiting oxidative stress.

To conclude, data from the literature show an undeniable role of testosterone on brain capillaries guaranteeing cerebral homeostasis in males, but they reflect complex actions of hormones which appear to be brain region-, state of health-, and/or dose-dependent. The cellular and molecular mechanisms underlying the maintenance of $\mathrm{BBB}$ integrity and the associated signaling pathways remain to be analyzed in greater detail.

Understanding the role of testosterone and testosterone signaling in the functions of cerebral blood vessels and the BBB could lead to the exploration of the therapeutic potential of testosterone in several CNS disorders. Indeed, this could partly answer the enigma of sex differences and of age-related emergence and progression of some CNS pathologies or dysfunctions.

It is also important to continue to explore this area of research, as this will lead to a better understanding of the action of environmental contaminants such as endocrine disruptors that interfere with normal hormonal balance and/or pathways and thus exert potentially deleterious effects on health. Considering the abundance of environmental contaminants that have antiandrogenic and/or antiestrogenic properties, consideration should be given to the effects of these components on brain microvessels.

\section{Acknowledgments}

We thank Dr. Sakina Mhaouty-Kodja (Neuroscience ParisSeine, Sorbonne University, Paris, France) for attentive reading and pertinent advice.

\section{Conflict of Interest Statement}

The authors declare no competing interests with respect to the research, authorship, and/or publication of this article.

\section{Author Contributions}

D. Ahmadpour wrote the manuscript with significant input from V. Grange-Messent. 


\section{References}

1 Larson TA. Sex Steroids, Adult Neurogenesis, and Inflammation in CNS Homeostasis, Degeneration, and Repair. Front Endocrinol (Lausanne). 2018 Apr;9:205.

2 Mhaouty-Kodja S. Role of the androgen receptor in the central nervous system. Mol Cell Endocrinol. 2018 Apr;465:103-12.

3 Picot M, Naulé L, Marie-Luce C, Martini M, Raskin K, Grange-Messent V, et al. Vulnerability of the neural circuitry underlying sexual behavior to chronic adult exposure to oral bisphenol a in male mice. Endocrinology. 2014 Feb;155(2):502-12.

4 Krause DN, Duckles SP, Gonzales RJ. Local oestrogenic/androgenic balance in the cerebral vasculature. Acta Physiol (Oxf). 2011 Sep;203(1):181-6.

5 Gonzales RJ, Ansar S, Duckles SP, Krause DN. Androgenic/estrogenic balance in the male rat cerebral circulation: metabolic enzymes and sex steroid receptors. J Cereb Blood Flow Metab. 2007 Nov;27(11):1841-52.

6 Liu M, Kelley MH, Herson PS, Hurn PD. Neuroprotection of sex steroids. Minerva Endocrinol. 2010 Jun;35(2):127-43.

7 Gold SM, Chalifoux S, Giesser BS, Voskuhl $\mathrm{RR}$. Immune modulation and increased neurotrophic factor production in multiple sclerosis patients treated with testosterone. J Neuroinflammation. 2008 Jul;5(1):32.

8 Spence RD, Voskuhl RR. Neuroprotective effects of estrogens and androgens in CNS inflammation and neurodegeneration. Front Neuroendocrinol. 2012 Jan;33(1):105-15.

9 Voskuhl R. Sex differences in autoimmune diseases. Biol Sex Differ. 2011 Jan;2(1):1.

10 Herndon JM, Tome ME, Davis TP. Chapter 9: Development and Maintenance of the BloodBrain Barrier. In: Caplan LR, Biller J, Leary MC, et al., editors. Primer on Cerebrovascular Diseases. 2nd ed. San Diego: Academic Press 2017. p. 51-6.

11 Abbott NJ, Patabendige AA, Dolman DE, Yusof SR, Begley DJ. Structure and function of the blood-brain barrier. Neurobiol Dis. 2010 Jan;37(1):13-25.

12 Archer DP, Ravussin PA. Role of blood-brain barrier in cerebral homeostasis. Ann Fr Anesth Reanim. 1994;13(1):57-61. French.

13 Erdő F, Denes L, de Lange E. Age-associated physiological and pathological changes at the blood-brain barrier: A review. J Cereb Blood Flow Metab. 2017 Jan;37(1):4-24.

14 Weiss N, Miller F, Cazaubon S, Couraud PO. The blood-brain barrier in brain homeostasis and neurological diseases. Biochim Biophys Acta. 2009 Apr;1788(4):842-57.

15 Blanchette M, Daneman R. Formation and maintenance of the BBB. Mech Dev. 2015 Nov;138(Pt 1):8-16.

16 Keaney J, Campbell M. The dynamic bloodbrain barrier. FEBS J. 2015 Nov;282(21): 4067-79.

17 Reinhold AK, Rittner HL. Barrier function in the peripheral and central nervous system - a review. Pflugers Arch. 2017 Jan;469(1):12334.

18 Greene C, Hanley N, Campbell M. Claudin-5: gatekeeper of neurological function. Fluids Barriers CNS. 2019 Jan;16(1):3.

19 Dias MC, Coisne C, Lazarevic I, Baden P, Hata M, Iwamoto N, et al. Publisher Correction: Claudin-3-deficient C57BL/6J mice display intact brain barriers. Sci Rep. 2019 Jul; 9(1):10702

20 Jia W, Lu R, Martin TA, Jiang WG. The role of claudin- 5 in blood-brain barrier (BBB) and brain metastases (review). Mol Med Rep. 2014 Mar;9(3):779-85.

21 Yang Y, Rosenberg GA. MMP-mediated disruption of claudin-5 in the blood-brain barrier of rat brain after cerebral ischemia. Methods Mol Biol. 2011;762:333-45.

22 Kook SY, Seok Hong H, Moon M, Mook-Jung I. Disruption of blood-brain barrier in $\mathrm{Alz}$ heimer disease pathogenesis. Tissue Barriers. 2013 Apr;1(2):e23993.

23 Chow BW, Gu C. The molecular constituents of the blood-brain barrier. Trends Neurosci. 2015 Oct;38(10):598-608.

24 Tietz S, Engelhardt B. Brain barriers: crosstalk between complex tight junctions and adherens junctions. J Cell Biol. 2015 May;209(4): 493-506.

25 Ballabh P, Braun A, Nedergaard M. The blood-brain barrier: an overview: structure, regulation, and clinical implications. Neurobiol Dis. 2004 Jun;16(1):1-13.

26 Obermeier B, Daneman R, Ransohoff RM. Development, maintenance and disruption of the blood-brain barrier. Nat Med. 2013 Dec; 19(12):1584-96.

27 Prevot V, Dehouck B, Sharif A, Ciofi P, Giacobini P, Clasadonte J. The Versatile Tanycyte: A Hypothalamic Integrator of Reproduction and Energy Metabolism. Endocr Rev. 2018 Jun;39(3):333-68.

28 Azzi S, Hebda JK, Gavard J. Vascular permeability and drug delivery in cancers. Front Oncol. 2013 Aug;3:211.

29 Girardin F. Membrane transporter proteins: a challenge for CNS drug development. Dialogues Clin Neurosci. 2006;8(3):311-21.

30 Liu L, Liu X. Contributions of Drug Transporters to Blood-Brain Barriers. In: Liu X, Pan G, editors. Drug Transporters in Drug Disposition, Effects and Toxicity. Singapore: Springer Singapore; 2019. p. 407-66.

31 Choudhuri S, Klaassen CD. Structure, function, expression, genomic organization, and single nucleotide polymorphisms of human ABCB1 (MDR1), ABCC (MRP), and ABCG2 (BCRP) efflux transporters. Int J Toxicol. 2006 Jul-Aug;25(4):231-59.

32 Löscher W, Potschka H. Blood-brain barrier active efflux transporters: ATP-binding cassette gene family. NeuroRx. 2005 Jan;2(1): 86-98.

33 De Bock M, Van Haver V, Vandenbroucke RE, Decrock E, Wang N, Leybaert L. Into rather unexplored terrain-transcellular transport across the blood-brain barrier. Glia. 2016 Jul;64(7):1097-123.

34 Deng J, Huang Q, Wang F, Liu Y, Wang Z, Wang Z, et al. The role of caveolin-1 in bloodbrain barrier disruption induced by focused ultrasound combined with microbubbles. J Mol Neurosci. 2012 Mar;46(3):677-87.

35 Ikezu T, Ueda H, Trapp BD, Nishiyama K, Sha JF, Volonte D, et al. Affinity-purification and characterization of caveolins from the brain: differential expression of caveolin-1, -2 , and -3 in brain endothelial and astroglial cell types. Brain Res. 1998 Sep;804(2):177-92.

36 von Tell D, Armulik A, Betsholtz C. Pericytes and vascular stability. Exp Cell Res. 2006 Mar; 312(5):623-9.

37 Armulik A, Abramsson A, Betsholtz C. Endothelial/pericyte interactions. Circ Res. 2005 Sep;97(6):512-23.

38 Sweeney MD, Ayyadurai S, Zlokovic BV. Pericytes of the neurovascular unit: key functions and signaling pathways. Nat Neurosci. 2016 May;19(6):771-83.

39 Peppiatt CM, Howarth C, Mobbs P, Attwell D. Bidirectional control of CNS capillary diameter by pericytes. Nature. 2006 Oct; 443(7112):700-4.

40 Armulik A, Genové G, Betsholtz C. Pericytes: developmental, physiological, and pathological perspectives, problems, and promises. Dev Cell. 2011 Aug;21(2):193-215.

41 Daneman R, Zhou L, Kebede AA, Barres BA. Pericytes are required for blood-brain barrier integrity during embryogenesis. Nature. 2010 Nov;468(7323):562-6.

42 Su X, Huang L, Qu Y, Xiao D, Mu D. Pericytes in Cerebrovascular Diseases: An Emerging Therapeutic Target. Front Cell Neurosci. 2019 Nov; 13:519.

43 Engelhardt B, Sorokin L. The blood-brain and the blood-cerebrospinal fluid barriers: function and dysfunction. Semin Immunopathol. 2009 Nov;31(4):497-511.

44 Hawkins BT, Davis TP. The blood-brain barrier/neurovascular unit in health and disease. Pharmacol Rev. 2005 Jun;57(2):173-85.

45 Wang CX, Shuaib A. Critical role of microvasculature basal lamina in ischemic brain injury. Prog Neurobiol. 2007 Oct;83(3):140-8.

46 Wolf SA, Boddeke HW, Kettenmann H. Microglia in Physiology and Disease. Annu Rev Physiol. 2017 Feb;79(1):619-43.

47 Alekseeva OS, Kirik OV, Gilerovich EG, Korzhevskii DE. Microglia of the Brain: Origin, Structure, Functions. J Evol Biochem Physiol. 2019;55(4):257-68

48 Davis EJ, Foster TD, Thomas WE. Cellular forms and functions of brain microglia. Brain Res Bull. 1994;34(1):73-8.

49 Johann S, Beyer C. Neuroprotection by gonadal steroid hormones in acute brain damage requires cooperation with astroglia and microglia. J Steroid Biochem Mol Biol. 2013 Sep;137:71-81. 
50 Sofroniew MV, Vinters HV. Astrocytes: biology and pathology. Acta Neuropathol. 2010 Jan;119(1):7-35.

51 Cabezas R, Ávila M, Gonzalez J, El-Bachá RS, Báez E, García-Segura LM, et al. Astrocytic modulation of blood brain barrier: perspectives on Parkinson's disease. Front Cell Neurosci. 2014 Aug;8:211.

52 Wong AD, Ye M, Levy AF, Rothstein JD, Bergles DE, Searson PC. The blood-brain barrier: an engineering perspective. Front Neuroeng. 2013 Aug;6:7.

53 DeBault LE, Cancilla PA. Gamma-glutamyl transpeptidase in isolated brain endothelial cells: induction by glial cells in vitro. Science. $1980 \mathrm{Feb} ; 207(4431): 653-5$

54 Zhao Z, Nelson AR, Betsholtz C, Zlokovic BV. Establishment and Dysfunction of the BloodBrain Barrier. Cell. 2015 Nov;163(5):1064-78.

55 Prasad S, Sajja RK, Naik P, Cucullo L. Diabetes Mellitus and Blood-Brain Barrier Dysfunction: an Overview. J Pharmacovigil. 2014 Jun;2(2):125.

56 Liu R, Pan MX, Tang JC, Zhang Y, Liao HB, Zhuang Y, et al. Role of neuroinflammation in ischemic stroke. Neuroimmunol Neuroinflamm. 2017;4(8):158.

57 Gonzales RJ. Androgens and the cerebrovasculature: modulation of vascular function during normal and pathophysiological conditions. Pflugers Arch. 2013 May;465(5):62742.

58 Vodo S, Bechi N, Petroni A, Muscoli C, Aloisi AM. Testosterone-induced effects on lipids and inflammation. Mediators Inflamm. 2013 2013:183041.

59 Feldman HA, Longcope C, Derby CA, Johannes $\mathrm{CB}$, Araujo AB, Coviello AD, et al. Age trends in the level of serum testosterone and other hormones in middle-aged men: longitudinal results from the Massachusetts male aging study. J Clin Endocrinol Metab. 2002 Feb;87(2):589-98.

60 Thibaut F. The role of sex and gender in neuropsychiatric disorders. Dialogues Clin Neurosci. 2016 Dec;18(4):351-2.

61 Lynch AM, Murphy KJ, Deighan BF, O’Reilly JA, Gun'ko YK, Cowley TR, et al. The impact of glial activation in the aging brain. Aging Dis. 2010 Dec;1(3):262-78

62 Lecce L, Lam YT, Lindsay LA, Yuen SC, Simpson PJ, Handelsman DJ, et al. Aging impairs VEGF-mediated, androgen-dependent regulation of angiogenesis. Mol Endocrinol. 2014 Sep;28(9):1487-501.

63 Sandoval KE, Witt KA. Age and $17 \beta$-estradiol effects on blood-brain barrier tight junction and estrogen receptor proteins in ovariectomized rats. Microvasc Res. 2011 Mar;81(2): 198-205.

64 Mahmoud R, Wainwright SR, Galea LA. Sex hormones and adult hippocampal neurogenesis: Regulation, implications, and potential mechanisms. Front Neuroendocrinol. 2016 Apr;41:129-52.

65 Ngun TC, Ghahramani N, Sánchez FJ, Bocklandt S, Vilain E. The genetics of sex differ- ences in brain and behavior. Front Neuroendocrinol. 2011 Apr;32(2):227-46.

66 Robison LS, Gannon OJ, Salinero AE, Zuloaga KL. Contributions of sex to cerebrovascular function and pathology. Brain Res. 2019 May; $1710: 43-60$

67 Atallah A, Mhaouty-Kodja S, Grange-Messent V. Chronic depletion of gonadal testosterone leads to blood-brain barrier dysfunction and inflammation in male mice. J Cereb Blood Flow Metab. 2017 Sep;37(9):3161-75.

68 Bielecki B, Mattern C, Ghoumari AM, Javaid S, Smietanka K, Abi Ghanem C, et al. Unexpected central role of the androgen receptor in the spontaneous regeneration of myelin. Proc Natl Acad Sci USA. 2016 Dec;113(51):14829-34.

69 Witt KA, Sandoval KE. Steroids and the blood-brain barrier: therapeutic implications. Adv Pharmacol. 2014;71:361-90.

70 Honda $\mathrm{H}$, Unemoto T, Kogo H. Different mechanisms for testosterone-induced relaxation of aorta between normotensive and spontaneously hypertensive rats. Hypertension. 1999 Dec;34(6):1232-6.

71 Orshal JM, Khalil RA. Gender, sex hormones, and vascular tone. Am J Physiol Regul Integr Comp Physiol. 2004 Feb;286(2):R233-49.

72 Ceballos G, Figueroa L, Rubio I, Gallo G, Garcia A, Martinez A, et al. Acute and nongenomic effects of testosterone on isolated and perfused rat heart. J Cardiovasc Pharmacol. 1999 May;33(5):691-7.

73 Masuda A, Mathur R, Halushka PV. Testosterone increases thromboxane $\mathrm{A} 2$ receptors in cultured rat aortic smooth muscle cells. Circ Res. 1991 Sep;69(3):638-43.

74 Costarella CE, Stallone JN, Rutecki GW, Whittier FC. Testosterone causes direct relaxation of rat thoracic aorta. J Pharmacol Exp Ther. 1996 Apr;277(1):34-9.

75 Yue P, Chatterjee K, Beale C, Poole-Wilson PA, Collins P. Testosterone relaxes rabbit coronary arteries and aorta. Circulation. 1995 Feb;91(4):1154-60.

76 Lorigo M, Mariana M, Lemos MC, Cairrao E. Vascular mechanisms of testosterone: the non-genomic point of view. J Steroid Biochem Mol Biol. 2020 Feb; 196:105496.

77 Bennett NC, Gardiner RA, Hooper JD, Johnson DW, Gobe GC. Molecular cell biology of androgen receptor signalling. Int J Biochem Cell Biol. 2010 Jun;42(6):813-27.

78 Melcangi RC, Poletti A, Cavarretta I, Celotti F, Colciago A, Magnaghi V, et al. The $5 a$-reductase in the central nervous system: expression and modes of control. J Steroid Biochem Mol Biol. 1998 Apr;65(1-6):295-9.

79 Patchev VK, Schroeder J, Goetz F, Rohde W, Patchev AV. Neurotropic action of androgens: principles, mechanisms and novel targets. Exp Gerontol. 2004 Nov-Dec;39(1112): $1651-60$

80 Shughrue PJ, Lane MV, Merchenthaler I. Comparative distribution of estrogen receptor- $\alpha$ and - $\beta$ mRNA in the rat central nervous system. J Comp Neurol. 1997 Dec; 388(4):507-25.
81 Simerly RB, Chang C, Muramatsu M, Swanson LW. Distribution of androgen and estrogen receptor mRNA-containing cells in the rat brain: an in situ hybridization study. J Comp Neurol. 1990 Apr;294(1):76-95.

82 Lauber AH, Mobbs CV, Muramatsu M, Pfaff DW. Estrogen receptor messenger RNA expression in rat hypothalamus as a function of genetic sex and estrogen dose. Endocrinology. 1991 Dec;129(6):3180-6.

83 Ohtsuki S, Tomi M, Hata T, Nagai Y, Hori S, Mori S, et al. Dominant expression of androgen receptors and their functional regulation of organic anion transporter 3 in rat brain capillary endothelial cells; comparison of gene expression between the blood-brain and -retinal barriers. J Cell Physiol. 2005 Sep; 204(3):896-900.

84 MacLusky NJ, Hajszan T, Prange-Kiel J, Leranth C. Androgen modulation of hippocampal synaptic plasticity. Neuroscience. 2006; 138(3):957-65.

85 Hussain R, Ghoumari AM, Bielecki B, Steibel J, Boehm N, Liere P, et al. The neural androgen receptor: a therapeutic target for myelin repair in chronic demyelination. Brain. 2013 Jan;136(Pt 1):132-46.

86 Forner S, Baglietto-Vargas D, Martini AC, Trujillo-Estrada L, LaFerla FM. Synaptic Impairment in Alzheimer's Disease: A Dysregulated Symphony. Trends Neurosci. 2017 Jun; 40(6):347-57.

87 Frye CA, Edinger KL, Seliga AM, Wawrzycki JM. 5alpha-reduced androgens may have actions in the hippocampus to enhance cognitive performance of male rats. Psychoneuroendocrinology. 2004 Sep;29(8):1019-27.

88 Jia JX, Cui CL, Yan XS, Zhang BF, Song W, Huo DS, et al. Effects of testosterone on synaptic plasticity mediated by androgen receptors in male SAMP8 mice. J Toxicol Environ Health A. 2016;79(19):849-55.

89 Brown TJ, Sharma M, Heisler LE, Karsan N, Walters MJ, MacLusky NJ. In vitro labeling of gonadal steroid hormone receptors in brain tissue sections. Steroids. 1995 Nov;60(11): 726-37.

90 Tabori NE, Stewart LS, Znamensky V, Romeo $\mathrm{RD}$, Alves SE, McEwen BS, et al. Ultrastructural evidence that androgen receptors are located at extranuclear sites in the rat hippocampal formation. Neuroscience. 2005; 130(1):151-63.

91 Leranth C, Petnehazy O, MacLusky NJ. Gonadal hormones affect spine synaptic density in the CA1 hippocampal subfield of male rats. J Neurosci. 2003 Mar;23(5):1588-92.

92 Hatanaka Y, Hojo Y, Mukai H, Murakami G, Komatsuzaki Y, Kim J, et al. Rapid increase of spines by dihydrotestosterone and testosterone in hippocampal neurons: dependence on synaptic androgen receptor and kinase networks. Brain Res. 2015 Sep;1621:121-32.

93 Xiao L, Jordan CL. Sex differences, laterality, and hormonal regulation of androgen receptor immunoreactivity in rat hippocampus. Horm Behav. 2002 Nov;42(3):327-36. 
94 Cohen LS, Soares CN, Vitonis AF, Otto MW, Harlow BL. Risk for new onset of depression during the menopausal transition: the Harvard study of moods and cycles. Arch Gen Psychiatry. 2006 Apr;63(4):385-90.

95 Galea LA, Wainwright SR, Roes MM, Duarte-Guterman P, Chow C, Hamson DK. Sex, hormones and neurogenesis in the hippocampus: hormonal modulation of neurogenesis and potential functional implications. J Neuroendocrinol. 2013 Nov;25(11): 1039-61.

96 McEwen BS. Stress and hippocampal plasticity. Annu Rev Neurosci. 1999;22(1):10522.

97 Salvador E, Shityakov S, Förster C. Glucocorticoids and endothelial cell barrier function. Cell Tissue Res. 2014 Mar;355(3):597605.

98 Handa RJ, Nunley KM, Lorens SA, Louie JP, McGivern RF, Bollnow MR. Androgen regulation of adrenocorticotropin and corticosterone secretion in the male rat following novelty and foot shock stressors. Physiol Behav. 1994 Jan;55(1):117-24.

99 Quillinan N, Deng G, Grewal H, Herson PS. Androgens and stroke: good, bad or indifferent? Exp Neurol. 2014 Sep;259:10-5.

100 Cheng J, Alkayed NJ, Hurn PD. Deleterious effects of dihydrotestosterone on cerebral ischemic injury. J Cereb Blood Flow Metab. 2007 Sep;27(9):1553-62.

101 Nakano T, Hurn PD, Herson PS, Traystman RJ. Testosterone exacerbates neuronal damage following cardiac arrest and cardiopulmonary resuscitation in mouse. Brain Res. 2010 Oct;1357:124-30.

102 Cheng J, Uchida M, Zhang W, Grafe MR, Herson PS, Hurn PD. Role of salt-induced kinase 1 in androgen neuroprotection against cerebral ischemia. J Cereb Blood Flow Metab. 2011 Jan;31(1):339-50.

103 Ishihara Y, Fujitani N, Sakurai H, Takemoto T, Ikeda-Ishihara N, Mori-Yasumoto K, et al. Effects of sex steroid hormones and their metabolites on neuronal injury caused by oxygen-glucose deprivation/reoxygenation in organotypic hippocampal slice cultures. Steroids. 2016 Sep;113:71-7.

104 Stephenson J, Nutma E, van der Valk P, Amor S. Inflammation in CNS neurodegenerative diseases. Immunology. 2018 Jun; 154(2):204-19.

105 Daneman R. The blood-brain barrier in health and disease. Ann Neurol. 2012 Nov; 72(5):648-72.

106 Hampton DW, Serio A, Pryce G, Al-Izki S, Franklin RJ, Giovannoni G, et al. Neurodegeneration progresses despite complete elimination of clinical relapses in a mouse model of multiple sclerosis. Acta Neuropathol Commun. 2013 Dec;1(1):84.

107 Liu W, Tang Y, Feng J. Cross talk between activation of microglia and astrocytes in pathological conditions in the central nervous system. Life Sci. 2011 Aug;89(5-6): 141-6.
108 Malkin CJ, Pugh PJ, Jones RD, Kapoor D, Channer KS, Jones TH. The effect of testosterone replacement on endogenous inflammatory cytokines and lipid profiles in hypogonadal men. J Clin Endocrinol Metab. 2004 Jul;89(7):3313-8.

109 Norata GD, Tibolla G, Seccomandi PM, Poletti A, Catapano AL. Dihydrotestosterone decreases tumor necrosis factor-alpha and lipopolysaccharide-induced inflammatory response in human endothelial cells. J Clin Endocrinol Metab. 2006 Feb;91(2):546-54.

110 Barreto G, Veiga S, Azcoitia I, Garcia-Segura LM, Garcia-Ovejero D. Testosterone decreases reactive astroglia and reactive microglia after brain injury in male rats: role of its metabolites, oestradiol and dihydrotestosterone. Eur J Neurosci. 2007 May;25(10): 3039-46.

111 Campelo AE, Cutini PH, Massheimer VL. Testosterone modulates platelet aggregation and endothelial cell growth through nitric oxide pathway. J Endocrinol. 2012 Apr; 213(1):77-87.

112 Lenz KM, McCarthy MM. Organized for sex - steroid hormones and the developing hypothalamus. Eur J Neurosci. 2010 Dec; 32(12):2096-104.

113 Sieveking DP, Chow RW, Ng MK. Androgens, angiogenesis and cardiovascular regeneration. Curr Opin Endocrinol Diabetes Obes. 2010 Jun;17(3):277-83.

114 Liao W, Huang W, Guo Y, Xin M, Fu X. Testosterone promotes vascular endothelial cell migration via upregulation of ROCK-2/ moesin cascade. Mol Biol Rep. 2013 Dec; 40(12):6729-35.

115 Liu P, Li X, Song F, Li P, Wei J, Yan Q, et al. Testosterone promotes tube formation of endothelial cells isolated from veins via activation of Smad1 protein. Mol Cell Endocrinol. 2017 May;446:21-31.

116 Sun Y, Jin K, Xie L, Childs J, Mao XO, Logvinova $\mathrm{A}$, et al. VEGF-induced neuroprotection, neurogenesis, and angiogenesis after focal cerebral ischemia. J Clin Invest. 2003 Jun;111(12):1843-51.

117 Chen Z, Ye R, Goldman SA. Testosterone modulation of angiogenesis and neurogenesis in the adult songbird brain. Neuroscience. 2013 Jun;239:139-48.

118 Dittrich F, Ramenda C, Grillitsch D, FranklVilches C, Ko MC, Hertel M, et al. Regulatory mechanisms of testosterone-stimulated song in the sensorimotor nucleus HVC of female songbirds. BMC Neurosci. 2014 Dec; 15:128.

119 Hall ZJ, Macdougall-Shackleton SA. Influence of testosterone metabolites on songcontrol system neuroplasticity during photostimulation in adult European starlings (Sturnus vulgaris). PLoS One. 2012;7(7): e40060.

120 Ohtsuki S, Asaba H, Takanaga H, Deguchi T, Hosoya K, Otagiri M, et al. Role of bloodbrain barrier organic anion transporter 3 (OAT3) in the efflux of indoxyl sulfate, a uremic toxin: its involvement in neurotransmitter metabolite clearance from the brain. J Neurochem. 2002 Oct;83(1):57-66.

121 Kobayashi Y, Hirokawa N, Ohshiro N, Sekine T, Sasaki T, Tokuyama S, et al. Differential gene expression of organic anion transporters in male and female rats. Biochem Biophys Res Commun. 2002 Jan; 290(1):482-7.

122 Giuliano F, Allard J. Dopamine and male sexual function. Eur Urol. 2001 Dec;40(6) 601-8.

123 Patching SG. Glucose Transporters at the Blood-Brain Barrier: Function, Regulation and Gateways for Drug Delivery. Mol Neurobiol. 2017 Mar;54(2):1046-77.

124 Banks WA. Brain meets body: the bloodbrain barrier as an endocrine interface. Endocrinology. 2012 Sep;153(9):4111-9.

125 Videbech P. PET measurements of brain glucose metabolism and blood flow in major depressive disorder: a critical review. Acta Psychiatr Scand. 2000 Jan;101(1):11-20.

126 Desai BS, Monahan AJ, Carvey PM, Hendey B. Blood-brain barrier pathology in Alzheimer's and Parkinson's disease: implications for drug therapy. Cell Transplant. 2007;16(3):285-99.

127 Shi J, Simpkins JW. 17 beta-Estradiol modulation of glucose transporter 1 expression in blood-brain barrier. Am J Physiol. 1997 Jun; 272(6 Pt 1):E1016-22.

128 Pan W, Stone KP, Hsuchou H, Manda VK, Zhang Y, Kastin AJ. Cytokine signaling modulates blood-brain barrier function. Curr Pharm Des. 2011 Nov; 17(33):3729-40.

129 Salkeni MA, Lynch JL, Otamis-Price T, Banks WA. Lipopolysaccharide impairs blood-brain barrier P-glycoprotein function in mice through prostaglandin- and nitric oxide-independent pathways. J Neuroimmune Pharmacol. 2009 Jun;4(2):276-82.

130 Miller DS, Bauer B, Hartz AM. Modulation of P-glycoprotein at the blood-brain barrier: opportunities to improve central nervous system pharmacotherapy. Pharmacol Rev. 2008 Jun;60(2):196-209.

131 Poller B, Drewe J, Krähenbühl S, Huwyler J, Gutmann H. Regulation of BCRP (ABCG2) and P-glycoprotein (ABCB1) by cytokines in a model of the human blood-brain barrier. Cell Mol Neurobiol. 2010 Jan;30(1):63-70.

132 Virgintino D, Robertson D, Errede M, Benagiano V, Tauer U, Roncali L, et al. Expression of caveolin-1 in human brain microvessels. Neuroscience. 2002;115(1):145-52.

133 Badaut J, Ajao DO, Sorensen DW, Fukuda $\mathrm{AM}$, Pellerin L. Caveolin expression changes in the neurovascular unit after juvenile traumatic brain injury: signs of blood-brain barrier healing? Neuroscience. 2015 Jan;285: 215-26.

134 Jasmin JF, Malhotra S, Singh Dhallu M, Mercier I, Rosenbaum DM, Lisanti MP. Caveolin-1 deficiency increases cerebral ischemic injury. Circ Res. 2007 Mar;100(5) $721-9$. 
135 Huang Q, Zhong W, Hu Z, Tang X. A review of the role of cav-1 in neuropathology and neural recovery after ischemic stroke. J Neuroinflammation. 2018 Dec;15(1):348.

136 Nag S, Venugopalan R, Stewart DJ. Increased caveolin-1 expression precedes decreased expression of occludin and claudin-5 during blood-brain barrier breakdown. Acta Neuropathol. 2007 Nov;114(5): 459-69.

137 Stamatovic SM, Keep RF, Wang MM, Jankovic I, Andjelkovic AV. Caveolae-mediated internalization of occludin and claudin-5 during CCL2-induced tight junction remodeling in brain endothelial cells. J Biol Chem. 2009 Jul;284(28):19053-66.

138 Chen HS, Chen X, Li WT, Shen JG. Targeting $\mathrm{RNS} /$ caveolin-1/MMP signaling cascades to protect against cerebral ischemiareperfusion injuries: potential application for drug discovery. Acta Pharmacol Sin. 2018 May;39(5):669-82.

139 Bennett N, Hooper JD, Lee CS, Gobe GC. Androgen receptor and caveolin-1 in prostate cancer. IUBMB Life. 2009 Oct;61(10): 961-70.

140 Lu ML, Schneider MC, Zheng Y, Zhang X, Richie JP. Caveolin-1 interacts with androgen receptor. A positive modulator of androgen receptor mediated transactivation. J Biol Chem. 2001 Apr;276(16):13442-51.

141 Baeten KM, Akassoglou K. Extracellular matrix and matrix receptors in blood-brain barrier formation and stroke. Dev Neurobiol. 2011 Nov;71(11):1018-39.

142 Fujimura M, Gasche Y, Morita-Fujimura Y, Massengale J, Kawase M, Chan PH. Early appearance of activated matrix metalloproteinase- 9 and blood-brain barrier disruption in mice after focal cerebral ischemia and reperfusion. Brain Res. 1999 Sep;842(1):92100.

143 Ridnour LA, Windhausen AN, Isenberg JS, Yeung N, Thomas DD, Vitek MP, et al. Nitric oxide regulates matrix metalloproteinase- 9 activity by guanylyl-cyclase-dependent and -independent pathways. Proc Natl Acad Sci USA. 2007 Oct;104(43):16898903.

144 Sekine-Aizawa Y, Hama E, Watanabe K, Tsubuki S, Kanai-Azuma M, Kanai Y, et al. Matrix metalloproteinase (MMP) system in brain: identification and characterization of brain-specific MMP highly expressed in cerebellum. Eur J Neurosci. 2001 Mar;13(5): 935-48.

145 Lakhan SE, Kirchgessner A, Tepper D, Leonard A. Matrix metalloproteinases and blood-brain barrier disruption in acute ischemic stroke. Front Neurol. 2013 Apr;4: 32.

146 Candelario-Jalil E, Thompson J, Taheri S, Grossetete M, Adair JC, Edmonds E, et al. Matrix metalloproteinases are associated with increased blood-brain barrier opening in vascular cognitive impairment. Stroke. 2011 May;42(5):1345-50.
147 Rempe RG, Hartz AM, Bauer B. Matrix metalloproteinases in the brain and bloodbrain barrier: versatile breakers and makers. J Cereb Blood Flow Metab. 2016 Sep;36(9): 1481-507.

148 Yang F, Zhao K, Zhang X, Zhang J, Xu B. ATP Induces Disruption of Tight Junction Proteins via IL-1 Beta-Dependent MMP-9 Activation of Human Blood-Brain Barrier In Vitro. Neural Plast. 2016;2016:8928530.

149 Dhanda S, Sandhir R. Blood-Brain Barrier Permeability Is Exacerbated in Experimental Model of Hepatic Encephalopathy via MMP-9 Activation and Downregulation of Tight Junction Proteins. Mol Neurobiol. 2018 May;55(5):3642-59.

150 Gu Y, Zheng G, Xu M, Li Y, Chen X, Zhu W, et al. Caveolin-1 regulates nitric oxide-mediated matrix metalloproteinases activity and blood-brain barrier permeability in focal cerebral ischemia and reperfusion injury. J Neurochem. 2012 Jan;120(1):147-56.

151 Berthiaume AA, Hartmann DA, Majesky MW, Bhat NR, Shih AY. Pericyte Structural Remodeling in Cerebrovascular Health and Homeostasis. Front Aging Neurosci. 2018 Jul;10:210.

152 Krause DN, Duckles SP, Pelligrino DA. Influence of sex steroid hormones on cerebrovascular function. J Appl Physiol (1985). 2006 Oct;101(4):1252-61.

153 Willems A, Batlouni SR, Esnal A, Swinnen JV, Saunders PT, Sharpe RM, et al. Selective ablation of the androgen receptor in mouse Sertoli cells affects Sertoli cell maturation, barrier formation and cytoskeletal development. PLoS One. 2010 Nov;5(11):e14168.

154 Sumi N, Nishioku T, Takata F, Matsumoto J Watanabe T, Shuto H, et al. Lipopolysaccharide-activated microglia induce dysfunction of the blood-brain barrier in rat microvascular endothelial cells co-cultured with microglia. Cell Mol Neurobiol. 2010 Mar;30(2):247-53.

155 Ronaldson PT, Davis TP. Blood-brain barrier integrity and glial support: mechanisms that can be targeted for novel therapeutic approaches in stroke. Curr Pharm Des. 2012; 18(25):3624-44.

156 Sasaki Y, Ohsawa K, Kanazawa H, Kohsaka $\mathrm{S}$, Imai Y. Iba1 is an actin-cross-linking protein in macrophages/microglia. Biochem Biophys Res Commun. 2001 Aug;286(2): 292-7.

157 Ito D, Imai Y, Ohsawa K, Nakajima K, Fukuuchi Y, Kohsaka S. Microglia-specific localisation of a novel calcium binding protein, Iba1. Brain Res Mol Brain Res. 1998 Jun;57(1):1-9.

158 Raivich G, Bohatschek M, Kloss CU, Werner A, Jones LL, Kreutzberg GW. Neuroglial activation repertoire in the injured brain: graded response, molecular mechanisms and cues to physiological function. Brain Res Brain Res Rev. 1999 Jul;30(1):77-105.

159 Parkhurst CN, Gan WB. Microglia dynamics and function in the CNS. Curr Opin Neurobiol. 2010 Oct;20(5):595-600.
160 Lenz KM, Nelson LH. Microglia and Beyond: Innate Immune Cells As Regulators of Brain Development and Behavioral Function. Front Immunol. 2018 Apr;9:698.

161 Liddelow SA, Guttenplan KA, Clarke LE, Bennett FC, Bohlen CJ, Schirmer L, et al. Neurotoxic reactive astrocytes are induced by activated microglia. Nature. 2017 Jan; 541(7638):481-7.

162 Hol EM, Pekny M. Glial fibrillary acidic protein (GFAP) and the astrocyte intermediate filament system in diseases of the central nervous system. Curr Opin Cell Biol. 2015 Feb;32:121-30.

163 Wilhelmsson U, Li L, Pekna M, Berthold $\mathrm{CH}$, Blom S, Eliasson C, et al. Absence of glial fibrillary acidic protein and vimentin prevents hypertrophy of astrocytic processes and improves post-traumatic regeneration. J Neurosci. 2004 May;24(21):5016-21.

164 Sherman MP, Griscavage JM, Ignarro LJ. Nitric oxide-mediated neuronal injury in multiple sclerosis. Med Hypotheses. 1992 Oct; 39(2):143-6.

165 Askalan R, Deveber G, Ho M, Ma J, Hawkins C. Astrocytic-inducible nitric oxide synthase in the ischemic developing human brain. Pediatr Res. 2006 Dec;60(6):687-92.

166 Liddelow SA, Barres BA. Reactive Astrocytes: Production, Function, and Therapeutic Potential. Immunity. 2017 Jun;46(6):957-67.

167 Hanisch UK, Kettenmann H. Microglia: active sensor and versatile effector cells in the normal and pathologic brain. Nat Neurosci. 2007 Nov;10(11):1387-94.

168 Cragnolini AB, Lampitella G, Virtuoso A, Viscovo I, Panetsos F, Papa M, et al. Regional brain susceptibility to neurodegeneration: what is the role of glial cells? Neural Regen Res. 2020 May;15(5):838-42.

169 Wood PL. Neuroinflammation: Mechanisms and Management. Berlin: Springer Science \& Business Media; 2002.

170 Acaz-Fonseca E, Avila-Rodriguez M, Garcia-Segura LM, Barreto GE. Regulation of astroglia by gonadal steroid hormones under physiological and pathological conditions. Prog Neurobiol. 2016 Sep;144:5-26.

171 Garcia-Segura LM, Melcangi RC. Steroids and glial cell function. Glia. 2006 Nov;54(6): 485-98.

172 Chapouly C, Tadesse Argaw A, Horng S, Castro K, Zhang J, Asp L, et al. Astrocytic TYMP and VEGFA drive blood-brain barrier opening in inflammatory central nervous system lesions. Brain. 2015 Jun;138(Pt 6):1548-67.

173 da Fonseca AC, Matias D, Garcia C, Amaral $\mathrm{R}$, Geraldo LH, Freitas C, et al. The impact of microglial activation on blood-brain barrier in brain diseases. Front Cell Neurosci. 2014 Nov;8:362.

174 Oldendorf WH, Cornford ME, Brown WJ. The large apparent work capability of the blood-brain barrier: a study of the mitochondrial content of capillary endothelial cells in brain and other tissues of the rat. Ann Neurol. 1977 May;1(5):409-17. 
175 Di Meo S, Reed TT, Venditti P, Victor VM. Role of ROS and RNS sources in physiological and pathological conditions. Oxid Med Cell Longev. 2016;2016:1245049.

176 Phaniendra A, Jestadi DB, Periyasamy L. Free radicals: properties, sources, targets, and their implication in various diseases. Indian J Clin Biochem. 2015 Jan;30(1):11-26.

177 Doll DN, Hu H, Sun J, Lewis SE, Simpkins JW, Ren X. Mitochondrial crisis in cerebrovascular endothelial cells opens the bloodbrain barrier. Stroke. 2015 Jun;46(6):16819.

178 Taylor JM, Main BS, Crack PJ. Neuroinflammation and oxidative stress: co-conspirators in the pathology of Parkinson's disease. Neurochem Int. 2013 Apr;62(5):803-19.

179 Rovira-Llopis S, Bañuls C, de Marañon AM, Diaz-Morales N, Jover A, Garzon S, et al. Low testosterone levels are related to oxidative stress, mitochondrial dysfunction and altered subclinical atherosclerotic markers in type 2 diabetic male patients. Free Radic Biol Med. 2017 Jul;108:155-62.

180 Ota H, Akishita M, Akiyoshi T, Kahyo T, Setou M, Ogawa S, et al. Testosterone deficiency accelerates neuronal and vascular aging of SAMP8 mice: protective role of eNOS and SIRT1. PLoS One. 2012;7(1):e29598.

181 Liguori I, Russo G, Curcio F, Bulli G, Aran L, Della-Morte D, et al. Oxidative stress, aging, and diseases. Clin Interv Aging. 2018 Apr;13:757-72.
182 Pintana H, Pongkan W, Pratchayasakul W, Chattipakorn N, Chattipakorn SC. Testosterone replacement attenuates cognitive decline in testosterone-deprived lean rats, but not in obese rats, by mitigating brain oxidative stress. Age (Dordr). 2015 Oct;37(5):84.

183 Haring R, Baumeister SE, Völzke H, Dörr M, Kocher T, Nauck M, et al. Prospective inverse associations of sex hormone concentrations in men with biomarkers of inflammation and oxidative stress. J Androl. 2012 Sep-Oct;33(5):944-50.

184 Toro-Urrego N, Garcia-Segura LM, Echeverria V, Barreto GE. Testosterone Protects Mitochondrial Function and Regulates Neuroglobin Expression in Astrocytic Cells Exposed to Glucose Deprivation. Front Aging Neurosci. 2016 Jun;8:152.

185 Grimm A, Mensah-Nyagan AG, Eckert A. Alzheimer, mitochondria and gender. Neurosci Biobehav Rev. 2016 Aug;67:89-101.

186 Túnez I, Feijóo M, Collado JA, Medina FJ, Peña J, Muñoz MC, et al. Effect of testosterone on oxidative stress and cell damage induced by 3-nitropropionic acid in striatum of ovariectomized rats. Life Sci. 2007 Mar; 80(13):1221-7.

187 Cunningham RL, Singh M, O’Bryant SE, Hall JR, Barber RC. Oxidative stress, testosterone, and cognition among Caucasian and Mexican-American men with and without Alzheimer's disease. J Alzheimers Dis. 2014; 40(3):563-73.

188 Barron AM, Fuller SJ, Verdile G, Martins $\mathrm{RN}$. Reproductive hormones modulate oxidative stress in Alzheimer's disease. Antioxid Redox Signal. 2006 Nov-Dec;8(11-12): 2047-59.
189 Alonso-Alvarez C, Bertrand S, Faivre B, Chastel O, Sorci G. Testosterone and oxidative stress: the oxidation handicap hypothesis. Proc Biol Sci. 2007 Mar;274(1611):81925.

190 Choudhary V, Kaddour-Djebbar I, Lakshmikanthan V, Ghazaly T, Thangjam GS, Sreekumar A, et al. Novel role of androgens in mitochondrial fission and apoptosis. $\mathrm{Mol}$ Cancer Res. 2011 Aug;9(8):1067-77.

191 Tostes RC, Carneiro FS, Carvalho MH, Reckelhoff JF. Reactive oxygen species: players in the cardiovascular effects of testosterone. Am J Physiol Regul Integr Comp Physiol. 2016 Jan;310(1):R1-14.

192 Kang J, Jia Z, Ping Y, Liu Z, Yan X, Xing G, et al. Testosterone alleviates mitochondrial ROS accumulation and mitochondria-mediated apoptosis in the gastric mucosa of orchiectomized rats. Arch Biochem Biophys. 2018 Jul;649:53-9.

193 Chignalia AZ, Schuldt EZ, Camargo LL, et al. Testosterone induces vascular smooth muscle cell migration by NADPH oxidase and c-Src-dependent pathways. Hypertension. 2012 Jun;59(6):1263-71.

194 Singh H, Cheng J, Deng H, Kemp R, Ishizuka T, Nasjletti A, et al. Vascular cytochrome P450 4A expression and 20-hydroxyeicosatetraenoic acid synthesis contribute to endothelial dysfunction in androgen-induced hypertension. Hypertension. 2007 Jul;50(1):123-9. 